A comparison of kinetic and kinematic variables during the mid-thigh pull and countermovement shrug, across loads.

Original Research

David Meechan $^{1,2 \#}$, Timothy J Suchomel ${ }^{3}$, John J McMahon ${ }^{1}$ and Paul Comfort ${ }^{1}$

\title{
Affiliations:
}

${ }^{1}$ Human Performance Laboratory, Directorate of Sport, Exercise, and Physiotherapy, University of Salford, Greater Manchester, United Kingdom

${ }^{2}$ Department of Elite Training Science and Technology Department, Hong Kong Sports Institute, Hong Kong, China

${ }^{3}$ Department of Human Movement Sciences, Carroll University, Waukesha, Wisconsin

\#Corresponding Author: David Meechan

Telephone: + 85255988396

Email: D.Meechan@edu.salford.ac.uk

Brief running head: mid-thigh pull vs. countermovement shrug

Funding Statement: No funding was received for this article.

Conflict of Interest Statement: There are no conflicts of interest concerning this article.

Abstract word count: 249

Manuscript word count: 5466

Number of tables and figures 3 tables and 5 figures 


\section{A comparison of kinetic and kinematic variables during the mid-thigh pull and countermovement shrug, across loads.}

\section{ABSTRACT}

This study compared kinetic and kinematic variables during the mid-thigh pull (MTP) and countermovement shrug (CMS). Eighteen men (age: $29.43 \pm 3.95$ years, height: $1.77 \pm 0.08 \mathrm{~m}$, body mass: $84.65 \pm 18.79 \mathrm{~kg}$, one repetition maximum [1RM] power clean: $1.02 \pm 0.18 \mathrm{~kg} . \mathrm{kg}^{-}$ $\left.{ }^{1}\right)$ performed the MTP and CMS at intensities of $40 \%, 60 \%, 80 \%, 100 \%, 120 \%$ and $140 \%$ $1 \mathrm{RM}$, in a progressive manner. Peak force $(\mathrm{PF})$, mean force $(\mathrm{MF})$, peak velocity $(\mathrm{PV})$, peak barbell velocity (BV), peak power, (PP), mean power (MP) and net impulse were calculated from force-time data during the propulsion phase. During the CMS, PF and MF were maximized at $140 \% 1 \mathrm{RM}$ and was significantly greater than the MTP at all loads $(\mathrm{p} \leq 0.001$, Hedges $g=0.66-0.90) ; \mathrm{p}<0.001, g=0.74-0.99$, respectively). PV and BV were significantly and meaningfully greater during the CMS compared to the MTP across all loads ( $p<0.001, g$ $=1.83-2.85 ; \mathrm{p}<0.001, g=1.73-2.30$, respectively). Similarly, there was a significantly and meaningfully greater PP and MP during the CMS, across all loads, compared to the MTP $(\mathrm{p}<$ $0.001, g=1.45-2.22 ; \mathrm{p}<0.001, g=1.52-1.92)$. Impulse during the CMS was also significantly greater across all loads $(\mathrm{p}<0.001, g=1.20-1.66)$ compared to the MTP. Results of this study demonstrate that the CMS may be a more advantageous exercise to perform to enhance forcetime characteristics when compared to the MTP, due to the greater kinetics and kinematic values observed. 


\section{INTRODUCTION}

Weightlifting exercises (snatch and clean and jerk) and their derivatives are commonly performed by athletes to develop rapid triple extension of the hips, knees, and ankles (plantar flexion). These movements are required by a vast majority of sports $(32,33)$ as they relate to both sprint and jump performance $(3,17)$. These exercises are implemented due to the similarities in sport-specific movements (i.e. rapid extension of hips, knees and ankles) (2), whilst concurrently developing rapid force production and power (28).

Research on weightlifting biomechanics demonstrated that the second pull phase produces the greatest force and power applied to the barbell, in experienced weightlifters during the clean and power clean $(12,27)$. Interestingly, recent research on weightlifting pulling derivatives (i.e. those that exclude the catch phase) indicate that such exercises may provide a comparable (4) or greater (33-35) training stimulus compared to catch derivatives. Moreover, pulling derivatives permit supra-maximal loads $(>100 \% 1$ repetition maximum [RM] of a catching derivative) to be performed $(6,7,19)$, which has shown to elicit greater peak force (PF), rate of force development (RFD) and impulse than loads $<1$ RM power clean $(6,7)$. This provides an overload stimulus of the triple extension movement, potentially producing superior strength-power characteristics $(32,33)$.

During the mid-thigh pull (MTP) from training blocks, Haff et al. (14) demonstrated that system peak power (PP) occurred at 80\% 1RM; however, lighter loads were not assessed. In contrast, Kawamori et al. (19) found that system PP was the highest with 60\% 1RM, in male collegiate weightlifters, compared to $30 \%, 60 \%, 90 \%$, and $120 \%$ of $1 \mathrm{RM}$ power clean. However, two studies by Comfort et al. $(6,7)$ demonstrated that system PP was maximized at $40 \%$ in collegiate subjects, with Comfort et al. (6) demonstrating no significant differences 
between $40 \%$ and $60 \%$. It should be noted that the subjects in the above studies by Comfort et al. $(6,7)$ did not start from the blocks which has been performed in previous studies $(14,19)$. Research into weightlifting derivatives have shown that an increase in load resulted in a decrease in velocity during the MTP performed from a static position $(6,7)$, and when initiated with a countermovement during the hang high pull (HHP) and jump shrug (JS) $(30,35)$, the greatest loads maximize PF and the lowest loads maximize velocity.

To date, no study has investigated the kinetic and kinematic differences between the MTP and countermovement shrug (CMS); a MTP initiated with a countermovement. The CMS has been described as a dynamic exercise that allows for greater overload during the top of the second pull by an ability to produce greater force at a higher velocity through the stimulation of the stretch-shortening cycle (SSC) (11). It would be useful to determine if the addition or exclusion of the countermovement affects kinetic and kinematic variables during such exercises, to determine which variation may be the most beneficial for enhancing force-time characteristics. Any differences between these movements are likely a result of the performance-enhancing effect of the SSC (36). The SSC muscle action produces a more powerful muscle action than that which would result from a concentric action alone and has been viewed as essential for many sporting activities (13), as a result of the summation of elastic energy and neurological potentiation via stimulation of the muscle spindle (36).

The purpose of this study was to compare kinetic and kinematic variables attained within and between the MTP and CMS, across loads of 40-140\% 1RM power clean. It was hypothesized that the CMS would result in higher values across all kinetic and kinematic variables. It was further hypothesized that mean and peak force and net impulse would increase with load while 
mean (MP) and peak power (PP), peak (PV) system velocity and peak barbell velocity (BV) would decrease with an increase in load, in line with previous research $(6,7)$.

\section{METHODS}

\section{Experimental Approach to the Problem}

This study employed a within-subject repeated-measures research design; whereby kinematic (peak system velocity and peak barbell velocity) and kinetic (peak and maat toce and power, and net impulse) variables were determined during the MTP and CMS. The abovementioned variables were measured by the subject performing all lifts on a force plate, and barbell velocity assessed with a linear position transducer (LPT), using progressive loads of 40, 60, 80, 100, 120, 140\% 1RM power clean (PC), to determine differences in kinematic and kinetic variables within and between variations across loads. Progressive loads were used to ensure ecological validity and to minimize risk of injury during the heavier loads. Prior to the experimental trials, subjects visited the strength and conditioning facility on 2 occasions, at the same time of day (5-7 days apart), to establish 1RM PC reliability, following the protocol previously used in similar research $(6,7)$ and all lifts were increased with a minimum of $2.5 \mathrm{~kg}$ increments. The MTP and CMS were performed on two separate days (5-7 days apart) in a randomized order to minimize fatigue. The subjects returned five to seven days later to perform the other variation following the abovementioned protocol.

\section{Subjects}

Eighteen male subjects from various team and individual sports such as rugby, soccer, martial arts, athletics and fencing (age $29.43 \pm 3.95$ years, height $1.77 \pm 0.08 \mathrm{~m}$, body mass $84.65 \pm$ $18.79 \mathrm{~kg}$, relative $1 \mathrm{RM}$ power clean $1.02 \pm 0.18 \mathrm{~kg} \cdot \mathrm{kg}^{-1}$, resistance training experience $5.9 \pm$ 
1.4 years, who participated in regular resistance training, including some experience with weightlifting derivatives, volunteered to participate in this study. Subjects were free from injury and provided written informed consent prior to the commencement of testing. Subjects were requested to perform no strenuous activity during the 48 hours before testing, maintain their normal dietary intake before each session, and to attend testing sessions in a hydrated state. This investigation received prior ethical approval from the Institutional Ethics Committee and conformed to the principles of the World Medical Association's Declaration of Helsinki.

\section{Procedures}

\section{One Repetition Maximum Power Clean Testing}

Subjects performed a dynamic warm-up that consisted of body weight squats, lunges, and dynamic stretching. Three sub-maximal PC efforts performed with decreasing volume (6-2 repetitions) and increasing loads (matched to the volume) before commencing their first 1RM attempt. The 1RM for each subject was then determined within five attempts (interspersed by 2-4 minutes of rest) by gradually increasing the load until an incomplete attempt occurred. All PC attempts began with the barbell on the lifting platform and ended with the barbell caught on the anterior deltoids in a semi-squat position above parallel (visually monitored and any attempt caught below this was disallowed). Testing was performed using a lifting platform (Hammer Strength, Ohio, USA); International Weightlifting Federation approved weightlifting barbell, and bumper plates (Eleiko, Halmsted, Sweden). The greatest load achieved across the 2 sessions was used to calculate the loads used during the MTP and CMS. An accredited strength and conditioning coach supervised all sessions. 


\section{Power Testing}

Each subject completed a standardized warm- up, low-intensity cycling for 5 minutes, followed by one set of three repetitions of the variation at 40\% 1RM PC. The subjects were then required to complete one randomly assigned variation (either MTP or CMS) at intensities of 40, 60, 80, 100,120 , and $140 \%$ of their pre-determined $1 \mathrm{RM}$ in a progressive order $(40-140 \%)$ to replicate the progression of loads that occur in training sessions. Three repetitions were performed at each load with 30-60 seconds of rest between repetitions and 3-4 minutes' rest between loads to minimize fatigue (18 repetitions total) in line with Comfort et al. $(6,7)$. The barbell was placed on the safety bars of the power cage in between all repetitions to prevent fatigue in both variations. Once the body was stabilized (verified by observing the subject and force-time data), the lift was initiated with the countdown " 3,2 , 1 go", and all subjects were instructed to exert maximal intent during each repetition. All lifts were performed in a power cage (Fitness Technology, Adelaide, Australia) on the Fitness Technology 700 ballistic measurement system with integrated force plate (400 Series) sampling at $600 \mathrm{~Hz}$, interfaced with a desktop computer and ballistic measurement software. Verbal encouragement was provided throughout testing. During all repetitions, subjects were required to use lifting straps for standardization and to reduce technique breakdown due to loss of grip at higher loads.

For the MTP (Figure 1a), the subjects lowered the barbell to mid-thigh, paused for three seconds to minimize the effect of the SSC and then performed the exercise, ensuring a triple extension of the hips, knees, and ankles (plantar flexion) and a shrug that moved the barbell in a vertical plane while maintaining elbow extension $(6,7)$. Any repetitions that were initiated with a countermovement (identified by visual inspection of the force-time data) were disallowed and repeated after a further 30-60 second rest period. Testing was finished upon successful completion of all the repetitions across all loads (18 repetitions). 
For the CMS (figure 1b), the subjects stood completely vertical with knees extended for three seconds and then transitioned to the mid-thigh position by flexing at the knees before immediately performing a rapid triple extension of the hips, knees and ankles and a shrug that moved the barbell in a vertical plane while maintaining elbow extension (i.e., second pull) in one continuous movement (11).

\section{*** Insert figure 1a here***}

\section{Force-Time Data Collection}

Raw vertical force-time data for each trial was exported as text files and analyzed using a customized Excel spreadsheet (version 2016, Microsoft Corp., Redmond, WA, USA). Prior to the onset of the pull, subjects were instructed to remain stationary on the force platform for one second to allow for subsequent determination of system weight (body weight + barbell weight) (25). For both pulls, vertical ground reaction force (VGRF) data was averaged across the first second while the subjects stood still (this average value represented system weight) and a force threshold was calculated from the VGRF during this same time-period. Specifically, the standard deviation of the VGRF across the first second was calculated and then multiplied by 5 and the resultant value represented the force threshold used to determine the onset of the pull (25). During the MTP and CMS, the onset of movement was deemed to have occurred $30 \mathrm{~ms}$ before the VGRF was exceeded and reduced by the force threshold, respectively (25). Velocity of the system (barbell + body) was calculated from VGRF force-time data. Specifically, the acceleration-time record (subtracting system weight from VGRF and then dividing this by system mass on a sample-by-sample basis) was numerically integrated using the trapezoid rule to yield the velocity-time record (25). Power applied to the system was calculated from product 
of system velocity and VGRF at each time point $(6,7)$. Net VGRF was integrated with respect to time (also using the trapezoid rule) to obtain the net impulse. As an unweighting and braking phase precedes the propulsion (triple extension) phase during the CMS, but is not included during the MTP, all force-time variables were further analyzed in the propulsion phase only. The propulsion phase of both pulls was deemed to have started when velocity exceeded 0.01 $\mathrm{m} . \mathrm{s}^{-1}$ and finished at peak velocity, which coincided with the end of the pull (22-24). Net PF, net MF, PV, PP, MP were defined as the maximum (for peaks) and average (for means) values attained during the propulsion phase (22-24).

Peak barbell velocity (BV) was measured via an LPT and was determined as the greatest velocity during the pull (GymAware Power Tool Kinetic Performance Technologies, Canberra, Australia) with data transmitted via Bluetooth ${ }^{\mathrm{TM}}$ to a tablet (iPad, Apple Inc., California, USA). The LPT recorded the displacement-time curve by determining changes in the position of the barbell (1), which sampled and time-stamped the changes in barbell position in $20 \mathrm{~ms}$ time points. Velocity and acceleration data were then calculated from the first and second derivative of the change in barbell position with respect to time.

\section{Statistical Analyses}

Statistical analyses were performed using Statistical Package for the Social Sciences software version 24 (SPSS, Chicago, Ill, USA). For each variable, the mean output of the three pull trials was taken forward for statistical analysis. A two-way fixed effect model intraclass correlation coefficients (ICC) and coefficients of variation (CV), calculated as standard deviation / mean multiplied by 100 and $95 \%$ confidence intervals (CI) were used to determine reliability and variability of performance measures. Minimal acceptable reliability was determined with an 
ICC $\geq 0.70$ and CV of $\leq 10 \%$ (8) (table 1). Distribution of data was analyzed via Shapiro-Wilks' test of normality, with differences between exercises determined using paired samples t-tests or Wilcoxon's test, at each load. Subsequently, the effect of load was determined via repeated measures analysis of variance (ANOVA) with Bonferroni post hoc analysis. Sphericity could not be assumed via Mauchly's test $(p>0.05)$ for all variables, and therefore GreenhouseGeisser adjustment was used. Standardized differences were calculated using Hedges' $g$ effect sizes as previously described (16) and interpreted according to Hopkins et al. (17) which defined values as trivial $(\leq 0.19)$, small $(0.20-0.59)$, moderate $(0.60-1.19)$, large $(1.20-1.99)$, and very large (2.0-4.0). An a priori alpha level was set at $p \leq 0.05$.

\section{RESULTS}

Power clean 1RM performances were highly reliable $(\mathrm{ICC}=0.99,[95 \% \mathrm{CI}=0.98-1.00], \% \mathrm{CV}$ $=1.8 \%[0.8-2.9 \%])$ between sessions $1(84.17 \pm 21.64 \mathrm{~kg})$ and $2(85.28 \pm 20.09 \mathrm{~kg})$. All MTP variables showed acceptable level of variability except $\mathrm{PP}$ at $40 \%$ and $60 \%(\mathrm{CV}=10.7 \%-13 \%)$ with acceptable reliability for all variables except MV at $60 \%(\mathrm{ICC}=0.67)$ and $100-140 \%$ $(\mathrm{ICC}=0.65-0.68)$. All CMS variables demonstrated acceptable reliability and variability with the exception MV at 40\% (ICC $=0.65)$ (Table 1). Descriptive statistics (Mean \pm Standard Deviation), 95\% confidence intervals and effect sizes for the MTP and CMS are shown in Tables 2 and 3. As MV was deemed unreliable, this was removed from further analysis. It is likely that the lower reliability observed in system velocity due to the small movements during the quiet standing phase which may vary across subjects. 


\section{Comparison between exercise variations}

There was a moderately and significantly greater PF during the CMS when compared to the MTP across all loads $(\mathrm{p} \leq 0.001, g=0.66-0.90)$ (Figure 2a). Similarly, MF in the CMS was moderately and significantly greater across all loads $(\mathrm{p}<0.001, g=0.74-0.99)$ (Figure 2b). PV during the CMS was significantly greater and of a large to very large magnitude, across all loads ( $\mathrm{p}<0.001, g=1.83-2.85$ ) compared to the MTP (Figure 3a). Peak BV in the CMS demonstrated large to very large significant differences across all loads ( $\mathrm{p}<0.001, g=1.73$ 2.30) (Figure 3b). There was a very large and significant difference in PP during the CMS across all loads when compared to the MTP $(\mathrm{p}<0.001, g=1.45-2.22)$ (Figure 4a). MP demonstrated a large and significant difference during the CMS across all loads when compared to the MTP ( $\mathrm{p}<0.001, g=1.52-1.92)$ (Figure 4b). Net impulse during CMS was significantly greater across all loads $(\mathrm{p}<0.001, \mathrm{~g}=1.20-1.66)$ with a large magnitude (Figure 5).

\footnotetext{
*** Insert Figure 2 around here***

*** Insert Figure 3 around here***

*** Insert Figure 4 around here***

*** Insert Figure 5 around here***
} 
***Insert Table 3 here***

\section{Effect of Load on Mid-Thigh Pull Kinetics and Kinematics}

Peak force progressively increased with load with the greatest load occurring at $140 \% 1 \mathrm{RM}$ (Table 2a), although this was not significantly greater than PF at $120 \% 1 \mathrm{RM}$, with small to large significant differences between all loads. Similarly, MF progressively increased as load increased, with the greatest MF achieved at 140\% 1RM, with small to large and significant differences between all loads (Table $2 b$ ).

Peak velocity was greatest at 60\% 1RM and showed a progressive decrease across loads (Table 2a). PV at $60 \% 1 \mathrm{RM}$ was moderately and significant greater compared to $100 \%$ and $120 \%$ 1RM, with a large significant difference compared to 140\% 1RM. There was no meaningful or significant difference in PV achieved across loads of 40-80\% 1RM. Peak BV was greatest at $40 \% 1 \mathrm{RM}$ and showed a progressive decrease across loads, which was moderately and significantly greater than $80 \% 1 \mathrm{RM}$, with large to very large significant differences compared to $100 \%, 120 \%$ and $140 \% 1 \mathrm{RM}$. Peak BV at $60 \% 1 \mathrm{RM}$ demonstrated a small yet nonsignificant decrease compared to $40 \% 1 \mathrm{RM}$ (Table $2 \mathrm{~b}$ ).

Peak power demonstrated progressive increase with an increase in load from 40-80\% with the highest PP occurring at $80 \% 1 \mathrm{RM}$ (Table $2 \mathrm{~b}$ ). PP at $80 \%$ demonstrated moderate significant differences with $40 \%$. Mean power demonstrated a progressive increase from $40-80 \%$ with the highest MP occurring at 120\% 1RM which was not significantly greater than any other load (Table 2b). Net impulse demonstrated a progressive increase with load with the greatest 
impulse occurring at 120\% 1RM (Table 2a)., which demonstrated moderate to large significant differences than $40 \%$ only (Table $2 b$ ).

\section{Effect of Load on Countermovement Shrug Kinetics and Kinematics}

Peak force progressively increased with load, with the greatest load occurring at $140 \% 1 \mathrm{RM}$ (Table 3a). Small to large significant differences occurred between all loads, other than 120140\% 1RM, where there was only a trivial and non-significant difference (Table 3b). Similarly, MF progressively increased as load increased, with the greatest MF achieved at $140 \% 1 \mathrm{RM}$ (Table 3a), with small to large and significant differences between all loads (Table 3b).

Peak velocity was greatest at 40\% 1RM and showed a progressive decrease across loads (Table 3a). Peak velocity at $40 \%$ was moderately and significantly greater compared to $100 \%$ and $120 \%$, with a large significant difference compared to $140 \% 1 \mathrm{RM}$. There was no meaningful or significant difference in PV achieved across loads of 60-80\% 1RM (Table 3b). Peak BV was greatest at 40\% 1RM and showed a progressive decrease across loads, with large to very large significant differences compared to $80-140 \%$ 1RM. Peak BV at $60 \% 1 \mathrm{RM}$ demonstrated a small yet non-significant decrease compared to 40\% 1RM (Table 3b).

Peak power showed a progressive increase from $40 \%$ to $120 \%$ and was maximized at $120 \%$. Peak power at $120 \%$ showed moderate to large significant differences with $40 \%$ to $60 \%$, and trivial to small non-significant differences with all other loads (Table 3b). Similarly, MP showed a progressive increase with load, with $140 \%$ resulting in the greatest power (Table $3 \mathrm{a}$ ). Mean power at $140 \%$ showed trivial to small non-significant differences with all loads (Table $3 b)$. 
Net impulse showed a progressive increase with load with maximal impulse occurring at $120 \%$. Net impulse at $120 \%$ showed a moderate significant difference to $40 \%$, and trivial to small non-significant differences with all other loads (Table 3b).

\section{DISCUSSION}

The primary aim of this study was to investigate the effect of the inclusion of a countermovement on kinetic and kinematic variables during the mid-thigh pull (CMS vs. MTP). The results reveal that the inclusion of the countermovement (CMS) results in a large and significantly greater performance in all dependent variables when compared to the MTP, in line with our hypothesis. To the authors' knowledge, this was the first study to compare the effects of the inclusion of a countermovement in weightlifting pulling derivatives. In line with our other hypotheses, an increase in load resulted in a decrease in velocity and an increase in force and impulse.

Meaningful significantly greater PF was observed during the CMS compared to the MTP, across all loads, and was maximized at $140 \%$ in both variations (Figure $2 \mathrm{a}$ ), in agreement with previous studies $(7,8)$. The PF reported in this study was lower than one study $(6)$, but greater than another (7), which may be a result of lifting competence and bodyweight differences considering the $1 \mathrm{RM}$ power clean values were similar between the current and previous studies. Additionally, the above studies demonstrated that PF increased by $8.8 \%$ and $10.6 \%$ (7) and $8.8 \%(8)$ across loads respectively, which is much lower than the $23 \%$ increase in this study. 
Similarly, MF was greater during the CMS compared to the MTP, at all loads, and progressively increased with an increase in load and was maximized at 140\% 1RM, with moderate to large differences between variations (figure 2b). The use of MF as a kinetic measure in weightlifting derivatives has not been fully investigated. Although valuable performance characteristics, peak variables only represent instantaneous points during a given movement. During sporting movements, force is applied over time and not instantaneously; therefore, further research is needed to support the use of MF as a kinetic measure. However, as both PF and MF showed a progressive increase with load and maximized at the greatest load in both the variations, practitioners can use either kinetic variable as their choice of force measurement.

Peak velocity during the CMS showed significantly and meaningfully greater velocity compared to the MTP across loads (figure 3a). The greatest PV in the MTP occurred at $60 \%$ 1RM, (table $2 \mathrm{a}$ ), and decreased from $27 \%$ from $60 \%$ to $140 \% 1 \mathrm{RM}$. During the CMS, PV was maximized at $40 \% 1 \mathrm{RM}$ (table $3 \mathrm{a}$ ) and decreased by $17 \%$ from $40 \%$ to $140 \% 1 \mathrm{RM}$. These results indicate that practitioners seeking to improve the velocity of a loaded triple extension movement should prescribe loads of $40-80 \%$ of $1 \mathrm{RM}$ PC during the MTP and CMS, but that the CMS is superior in terms of the actual velocities achieved (figure $3 \mathrm{a}$ ).

The peak velocities in this study are lower than the hang power clean (HPC), HHP and JS peak COM velocities across loads of 30, 45, 65 and 80\% 1RM PC as previously reported (35). Load PV main effect sizes showed that at $45 \%\left(>1.6 \mathrm{~m} \cdot \mathrm{s}^{-1}\right), 65 \%\left(>1.6 \mathrm{~m} \cdot \mathrm{s}^{-1}\right), 80 \%\left(>1.5 \mathrm{~m} \cdot \mathrm{s}^{-1}\right)$ 1RM (HPC), greater PV were produced during the HPC, HHP and JS when compared to this study at similar loads, however loads of $>80 \%$ were not assessed. However, careful consideration must be made when directly comparing these findings to the above study as there 
are large differences in strength levels, assessed via 1RM PC. In addition, the HPC, HHP and JS started in the mid-thigh position and utilized a countermovement to the knee as opposed to the mid-thigh position in this study, and therefore had a greater distance and duration to accelerate the barbell.

Further, the JS is a weightlifting pulling derivative where the subject leaves the ground and therefore accelerates through a full range of motion through to take off (33). However, during the MTP and CMS and particularly at lower loads, there is likely a deceleration phase during the concentric phase as the subjects were encouraged not to jump off the platform. The PV values reported in this study are lower than the values reported previously which investigated kinematics and kinetics of the JS $(30,35)$. Therefore, at lower loads, the JS may be a better exercise to develop greater velocities than the MTP and CMS.

Peak BV in the CMS demonstrated large to very large significant differences across all loads compared to the MTP (Figure 3b). The greatest peak BV during the MTP occurred at $40 \%$ and was significantly greater than all loads except $60 \%$. During the CMS, peak PV was maximized at $40 \% 1 \mathrm{RM}$ which showed a very large significant difference than all loads except than $60 \%$ 1RM (Table 3b).

The peak BV results are lower than the peak BV reported previously $(6,7)$, with Comfort et al. $(7,8)$ reporting a decrease in MTP peak BV of $69 \%$ and $49 \%$ from $40 \% 1 \mathrm{RM}$ to $140 \% 1 \mathrm{RM}$ respectively, whilst this study showed a decrease of 37\% for MTP (table 2a) and 35\% for CMS (Table 3a); which may be a result of lifting competency between subjects. Although 1RM PC measurements are similar between studies, at the lower loads, it may be plausible that the subjects found it difficult in performing and coordinating weightlifting derivatives at loads that 
could be considered warm up loads (40-60\%), which ultimately resulted in lower peak BV than previously reported. It is also worth considering the ability of participants to perform maximal effort pulling derivatives with loads as light as 40\% 1RM the same way they would perform at supra-maximal loads.

Measurement of velocity in weightlifting derivatives are generally performed with a force plate or $\operatorname{LPT}(6,7,30,31,35)$. Moreover, devices that measure barbell velocity (i.e., LPT and accelerometers) are generally cheaper, easier to transport and much more accessible to practitioners. The findings of this study showed that both system velocity and barbell velocity generally showed a progressive decrease with load, therefore showing a similar trend. Although the peak BV resulted in greater velocities than PV, this may give an insight into the change in system velocity over loads. From a practical standpoint, as the system and bar velocities are different, practitioners should not use the devices interchangeably (21). It is likely that the lower reliability observed in system velocity compared to barbell velocity is likely because system velocity is calculated from force-time data, which assumes that velocity is zero during the period of quiet standing, which can vary, therefore, reducing reliability. This is more sensitive than the displacement-time data, where subtle changes in posture are unlikely to be sufficient for the LPT to identify movement and therefore a change in velocity.

There was significantly greater PP observed during the CMS compared to the MTP across all loads with large to very large effect sizes, highlighting the stimulation of the SSC allows for greater power to be produced as the athlete can overcome a greater force at a greater velocity (11). Therefore, it is recommended that strength and conditioning coaches should use the CMS when targeting power development as it may be preferred to the MTP. 
Peak power during the MTP was maximized at $80 \%(2063 \pm 491 \mathrm{~W}) 1 \mathrm{RM}$ (table 2$)$. This is in contrast to the studies by Comfort et al. $(6,7)$ who reported that PP was maximized at $40 \%$ in both studies, with considerably higher PP values reported (3712.82 $\pm 254.38 \mathrm{~W})$ and $(5451 \pm$ 1552.3 W) respectively. Surprisingly, during the CMS, PP were maximized at $120 \% 1 \mathrm{RM}$, (table 3). These findings suggest that higher loads are required to generate maximal power in the MTP and CMS. Given that PP was maximized at different loads in the both exercises, these findings agree with Soriano et al. (26) who suggests that the optimal load for power development may be exercise specific.

These findings are not in agreement with Kawamori et al. (19) who reported system PP (2228.9 $\pm 192.3 \mathrm{~W}$ ) was greatest at $60 \%$ of $1 \mathrm{RM}$ when comparing loads of $30,60,90,120 \%$ of $1 \mathrm{RM}$, however no significant difference between loads was reported. Further, Kawamori et al. (19) used collegiate weightlifters which may partially explain power at the higher loads due to an increase competency in weightlifting derivatives. However, whilst the present study did not utilize weightlifters, PP was maximized at higher loads (80-120\%) (figure 4a) which may be partly explained by the inexperience of the subjects performing these movements at such high loads, with lower percentages typically observed when training the power clean (15).

The optimal load for PP achieved in this study for the MTP is in line with PP achieved during the HPC and PC exercise $(9,10,20,31)$. However, several studies indicated that no statistical differences existed between the loads that produced the greatest PP at 60-80\% 1RM (5), 50$90 \%(10,18,20)$ and $30-80 \%(31)$.

It has been suggested that strength levels may influence the load that PP is obtained (29). Stone et al. (29) demonstrated that stronger athletes produced PP at 40\% 1RM when compared to weaker athletes $(10 \% 1 \mathrm{RM})$ in the jump squat, when power was assessed via inverse dynamics. 
In this study, the average $1 \mathrm{RM}$ PC $85.8 \pm 21.7 \mathrm{Kg}$ is similar $87.6 \pm 8.5 \mathrm{Kg}$ when compared to previous research (6), which would suggest no strength differences between studies. However, within this study, individual $1 \mathrm{RM}$ PC ranged from $55 \mathrm{~kg}$ to $140 \mathrm{~kg}$ which shows a large variance in strength levels which may help to explain the similar values in PP across loads $(1789 \pm 537 \mathrm{~W}$ to $2063 \pm 491 \mathrm{~W})$ and PP attained at higher load. These findings highlight that PP may occur over a spectrum of loads as previously reported $(5,18,20)$. Therefore, as an athlete gets stronger, strength and conditioning coaches may be able to prescribe greater loads that will maximize power production. It should be noted that although reliable measures, there was high variability in MTP PP at 40 and 60\% (Table 1).

During the CMS, MP was meaningfully and significantly greater than compared to the MTP at all loads (Figure 4b). Surprisingly, during the CMS, MP showed a progressive increase with load, with $140 \%$ resulting in the greatest power (table $3 a$ ). This is likely explained by the fact that MF increased by $25.7 \%$, whilst velocity decreased by $22.4 \%$ across loads (Table $3 \mathrm{a}$ ). Similarly, during the MTP, the greatest MP occurred at 120\% 1RM (table 2). MF increased by $30 \%$ from $40-140 \%$, whilst velocity decreased by $26.4 \%$ (Table $2 a$ ). The subjects in this study appeared to accelerate loads faster, due to the relatively proportionate increases in forces and decrease in velocities, MP may be improved over a spectrum of loads. Moreover, the fact that there was not a large decrement in velocity at the heavier loads may suggest that the subjects are capable of a higher 1RM power clean, however they may be limited by their ability to catch the barbell proficiently.

The CMS resulted in a large and significantly greater net impulse compared to the MTP across all loading conditions (figure 5) and is likely due to the greater magnitudes of forces produced over greater duration through the inclusion of the countermovement. In this study, MTP net 
impulse showed a progressive increase with load and was maximized at $120 \%$ (table $2 \mathrm{a}$ ), which was not statistically different to $60-100 \%$ and $140 \%$ (table $2 \mathrm{~b}$ ) which is in agreement with Comfort et al. $(6,7)$ who also demonstrated that impulse was maximized at higher loads (140\%). This is expected, given that PF and MF were maximized at the greatest loads. In agreement to this study, Comfort et al. (6) demonstrated that although impulse was maximized at $140 \%$, it was not significantly different to $80-120 \%$. Similarly, during the CMS, impulse increased with load and was maximized at 120\% 1RM (table 3a). As impulse has been shown to have a perfect correlation to jump height and is strongly related to change of direction and agility tasks (37), the use of the CMS may be preferred to the MTP when the focus is improving the aforementioned athletic tasks due to the greater impulse achieved at the same loads.

The findings of this study are not without their limitations. This study and previous studies calculated percentages based off the 1RM power clean which includes the catch phase $(6,7)$. The MTP and CMS exercises theoretically have a greater 1RM based on the decreased displacement and range of motion (32), and therefore there may be discrepancies in the effort that is produced. As loads of true maximal effort during pulling variations have not yet been investigated, the load percentages may not be a true reflection of weightlifting pulling ability, and may in fact result in a greater 1RM, and therefore greater loads during testing. The authors acknowledge that it may impractical to perform 1RM tests for certain movements due to the absence of criteria for what determines a successful repetition. Finally, future research should focus on investigating force-time characteristics with trained weightlifters to observe if similar results are produced during the CMS. 


\section{PRACTICAL APPLICATIONS}

It is imperative for $\mathrm{S} \& \mathrm{C}$ practitioners to select exercises that maximizes their athletes' capabilities and identify which strength quality is the primary focus. The CMS results in consistently higher kinetic and kinematic variables compared to the MTP across all loads. The results of this study demonstrate that the greatest peak velocities range from $40-60 \% 1 \mathrm{RM}$ power clean during both the MTP and CMS. In contrast, force and impulse are maximized at the higher loads of $120-140 \% 1 \mathrm{RM}$. Additionally, if the goal is to maximize peak power output, loads of $80-120 \% 1 \mathrm{RM}$ power clean are recommended during the MTP and CMS, whilst mean power production was maximized at $120-140 \%$. Furthermore, it is important to note that in order to train the entire force velocity continuum, a range of loads should be prescribed, in a periodized manner, incorporating a variety of exercises, as it appears that the optimal load for power production is exercise specific $(26,32)$.

\section{ACKNOWLEDGEMENTS}

The authors would like to thank the participants for their time and efforts. The authors report no conflict of interest and the results of the current study does not constitute endorsement of the product by the authors, the journal, or the National Strength and Conditioning Association. 


\section{REFERENCES}

1. Banyard HG, Nosaka K, Sato K, and Haff GG. Validity of Various Methods for Determining Velocity, Force and Power in the Back Squat. Int J Sports Physiol Perform 12: 1170-1176, 2017.

2. Canavan PK, Garrett GE, and Armstrong LE. Kinematic and kinetic relationships between an Olympic-style lift and the vertical jump. J Strength Cond Res 10: 127-130, 1996.

3. Carlock JM, Smith SJ, Hartman MJ, Morris RT, Ciroslan DA, Pierce KC, Newton RU, Harman EA, Sands WA, and Stone MH. The relationship between vertical jump power estimates and weightlifting ability: A field-test approach. J Strength Cond Res 18: 534539, 2004.

4. Comfort P, Allen M, and Graham-Smith P. Kinetic comparisons during variations of the power clean. J Strength Cond Res 25: 3269-3273, 2011.

5. Comfort P, Fletcher C, and McMahon JJ. Determination of optimal loading during the power clean, in collegiate athletes. J Strength Cond Res 26: 2970-2974, 2012.

6. Comfort P, Jones PA, and Udall R. The effect of load and sex on kinematic and kinetic variables during the mid-thigh clean pull. Sports Biomech 14: 139-156, 2015.

7. Comfort P, Udall R, and Jones PA. The effect of loading on kinematic and kinetic variables during the midthigh clean pull. J Strength Cond Res 26: 1208-1214, 2012.

8. Cormack SJ, Newton RU, and McGuigan MR. Neuromuscular and endocrine responses of elite players to an Australian rules football match. Int J Sports Physiol Perform 3: 359-374, 2008.

9. Cormie P, McBride JM, and McCalluey GO. Validation of power measurement techniques in dynamic lower body resistance exercises. J Appl Biomech 23: 103-118, 2007.

10. Cormie P, McCaulley GO, Triplett NT, and McBride JM. Optimal loading for maximal power output during lower-body resistance exercises. Med Sci Sports Exerc 39: 340349, 2007.

11. DeWeese BH and Scruggs SK. The Countermovement Shrug. Strength Cond J 0: 1-4, 2012.

12. Enoka RM. The pull in Olympic Weightlifting. Med Sci Sports 11: 131-137, 1979.

13. Flanagan EP and Comyns TM. The use of contact time and the reactive strength index to optimise fast stretch-shortening cycle training. Strength Cond J 30, 2008.

14. Haff GG, Stone M, O'Bryant HS, Harman. E, Dinan C, Johnson R, and Ki- Hoon H. Force-Time Dependent Characteristics of Dynamic and isometric muscle actions. $J$ Strength Cond Res 11: 269-272, 1997.

15. Hardee JP, Lawrence MM, Zwetsloot KA, Triplett NT, Utter AC, and McBride JM. Effect of cluster set configurations on power clean technique. J Sports Sci 31: 488-496, 2013.

16. Hedges L and Olkin I. Statistical Methods for Meta-Analysis. New York: Academic Press, Inc, 1985.

17. Hori N, Newton RU, Andrews WA, Kawamori N, McGuigan MR, and Nosaka K. Does performance of hang power clean differentiate performance of jumping, sprinting, and changing of direction?. J Strength Cond Res 22: 412-418, 2008.

18. Kawamori N, Crum AJ, Blumert PA, Kulik JR, Childers JT, Wood JA, Stone MH, and Haff GG. Influence of different relative intensities on power output during the hang power clean: identification of the optimal load. J Strength Cond Res 19: 698-708, 2005. 
19. Kawamori N, Rossi SJ, Justice BD, Haff EE, Pistilli EE, O’Bryant HS, Stone MH, and Haff GG. Peak force and rate of force development during isometric and dynamic midthigh clean pulls performed at various intensities. J Strength Cond Res 20: 483-491, 2006.

20. Kilduff LP, Bevan H, Owen N, Kingsley MI, Bunce P, Bennett M, and Cunningham D. Optimal loading for peak power output during the hang power clean in professional rugby players. Int J Sports Physiol Perform 2: 260-269, 2007.

21. Lake J, Lauder M, and Smith N. Barbell kinematics should not be used to estimate power output applied to the barbell- and-body system center of mass during lower-body resistance exercise. J Strength Cond Res 26: 1302-1307, 2012.

22. McMahon JJ, Jones PA, Dos' Santos T, and Comfort P. Influence of Dynamic Strength Index on Countermovement Jump Force-, Power-, Velocity-, and Displacement-Time Curves. Sports 5: 1-11, 2017.

23. McMahon JJ, Murphy S, Rej SJE, and Comfort P. Countermovement-Jump-Phase Characteristics of Senior and Academy Rugby League Players. Int J Sports Physiol Perform 12: 803-811, 2017.

24. McMahon JJ, Rej SJE, and Comfort P. Sex Differences in Countermovement Jump Phase Characteristics. Sports (Basel, Switzerland) 5, 2017.

25. Owen N, Watkins J, Kilduff L, Bevan H, and Bennett M. Development of a criterion method to determine peak mechanical power output in a countermovement jump. $J$ Strength Cond Res 28: 1152-1158, 2014.

26. Soriano MA, Jimenez-Reyes P, Rhea M, and Marın P. The Optimal Load for Maximal Power Production During Lower-Body Resistance Exercises: A Meta-Analysis. Sports Med 45: 1191-1205, 2015.

27. Souza AL, Shimada SD, and Koontz A. Ground reaction forces during the power clean. J Strength Cond Res 16: 423-427, 2002.

28. Stone M, Stone M, and Sands W. Principles and Practice of Resistance Training. Champaign, IL: Human Kinetics, 2007.

29. Stone MH, O'Bryant HS, McCoy L, Coglianese R, Lehmkuhl M, and Schilling B. Power and maximum strength relationships during performance of dynamic and static weighted jumps. J Strength Cond Res 17: 140-147, 2003.

30. Suchomel TJ, Beckham GK, and Wright GA. Lower body kinetics during the jump shrug: impact of load. J Trainology 2: 19-22, 2013.

31. Suchomel TJ, Beckham GK, and Wright GA. The impact of load on lower body performance variables during the hang power clean. Sports Biomech 13: 87-95, 2014.

32. Suchomel TJ, Comfort P, and Lake JP. Enhancing the force-velocity profile of athletes using weightlifting derivatives. Strength Cond J 0: 1-11, 2017.

33. Suchomel TJ, Comfort P, and Stone MH. Weightlifting Pulling Derivatives: Rationale for Implementation and Application. Sports Med 45: 823-839, 2015.

34. Suchomel TJ and Sole CJ. Force-Time-Curve Comparison Between Weight-Lifting Derivatives. Int J Sports Physiol Perform 12: 431-439, 2017.

35. Suchomel TJ, Wright GA, Kernozek TW, and Kline DE. Kinetic Comparison of the Power Development Between Power Clean Variations. J Strength Cond Res 28: 350360, 2014.

36. Turner AN and Jeffreys I. The Stretch-Shortening Cycle: Proposed Mechanisms and Methods for Enhancement. Strength Cond J 32: 87-99, 2010.

37. Winter EM, Abt G, Brookes FBC, Challis JH, Fowler NE, Knudson DV, Knuttgen HG, Kraemer WJ, Lane AM, Mechelen WV, Morton RH, Newton RU, Williams C, and Yeadon MR. Misuse of "Power" and other mechanical terms in sport and exercise science research. J Strength Cond Res 30: 292-300, 2016. 


\section{Figure and Table Legends}

Figure 1: a): Sequence of mid-thigh pull and b) Sequence of countermovement shrug

Figure 2: Comparison of, a) peak force and b) mean force between the countermovement shrug and mid-thigh pull across loads

Figure 3: Comparison of, a) peak velocity and b) peak barbell velocity between the countermovement shrug and mid-thigh pull across loads

Figure 4: Comparison of, a) peak power and b) mean power between the countermovement shrug and mid-thigh pull across loads

Figure 5- Comparison of Impulse between countermovement shrug and mid-thigh pull across loads

Table 1: Reliability (ICC [95\% confidence intervals) and variability (\%CV) $[95 \%$ confidence intervals) of kinetic and kinematic variables during the countermovement shrug and mid-thigh pull

Table 2: a): Descriptive statistics (mean, standard deviation and 95\% confidence intervals) for the mid-thigh pull and b) Comparisons of kinetic and kinematic variables between loads during the mid-thigh pull using Hedges' g effect size

Table 3: a): Descriptive statistics (mean, standard deviation and 95\% confidence intervals) for the countermovement shrug and b) Comparison of kinetic and kinematic variables between loads during the Countermovement Shrug using Hedges' g effect sizes 
Figure 1(a) Sequence of Mid-Thigh Pull
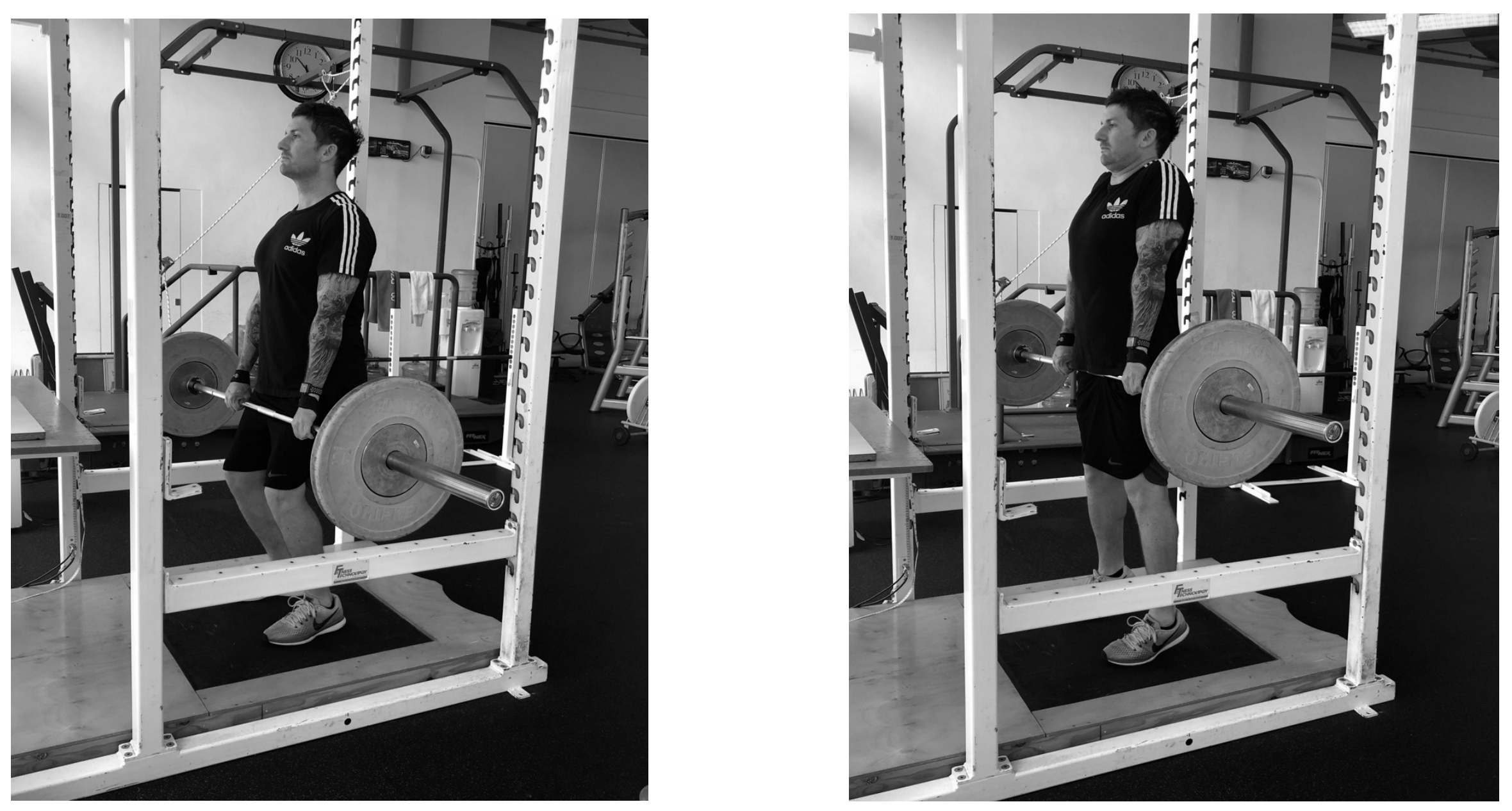
Figure 1(b) Sequence of Countermovement Shrug
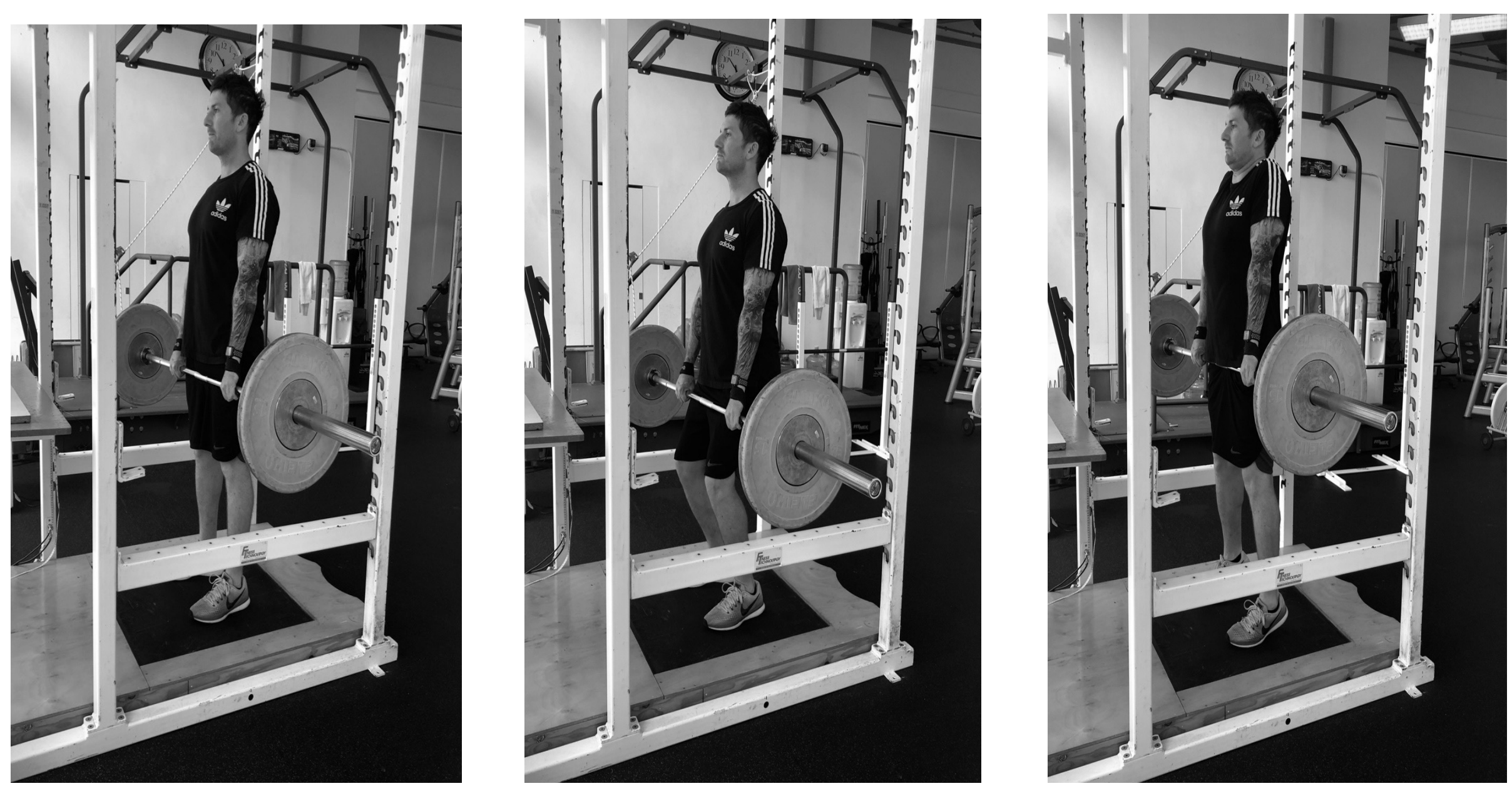

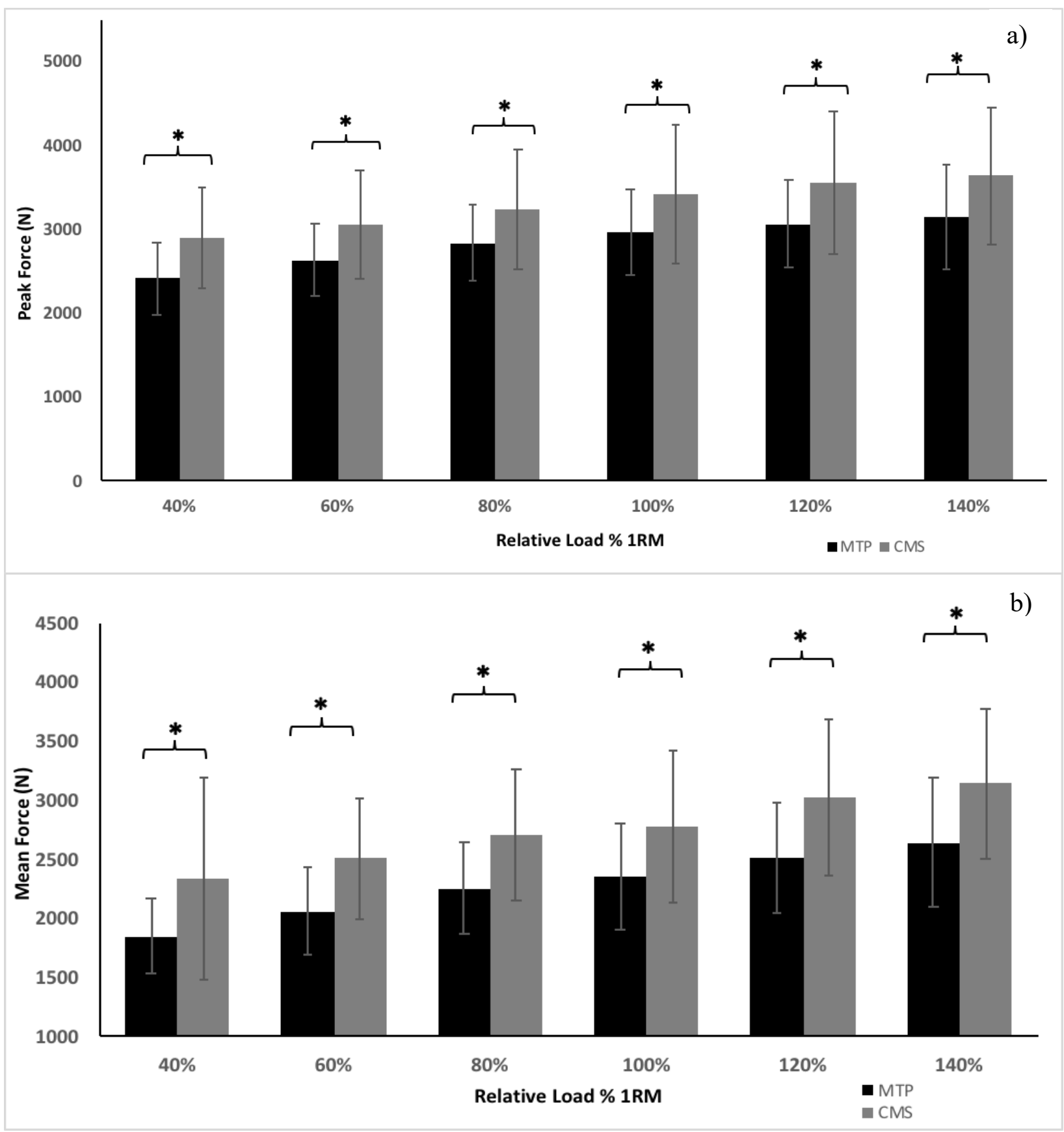

* Significantly greater than MTP $(p \leq 0.001)$

Figure 2: Comparison of, a) peak force and b) mean force between the countermovement shrug and mid-thigh pull across loads 


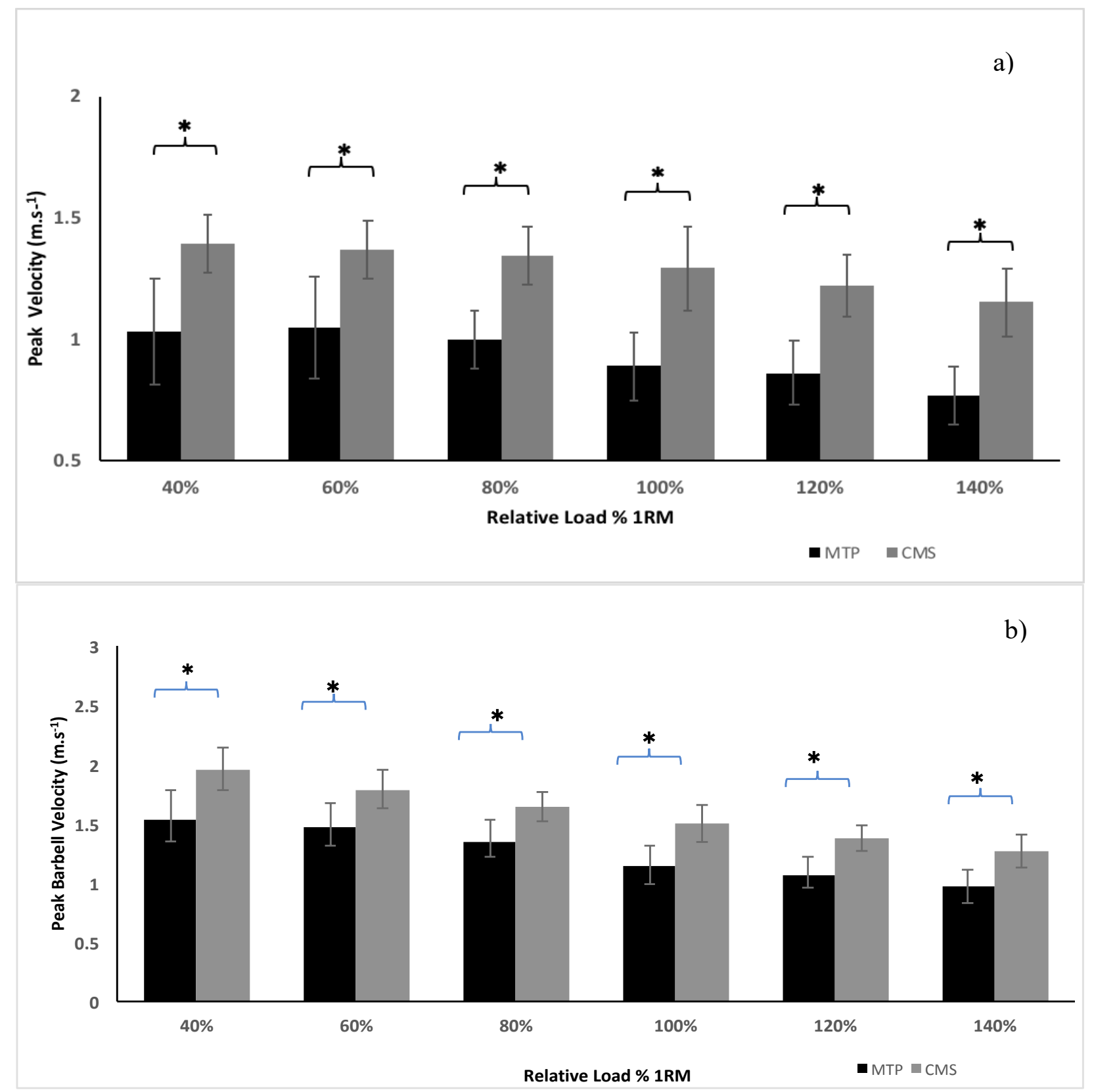

*Significantly greater than MTP $(\mathrm{p}<0.001)$

Figure 3: Comparison of, a) peak velocity and b) peak barbell velocity between the countermovement shrug and mid-thigh pull across loads 


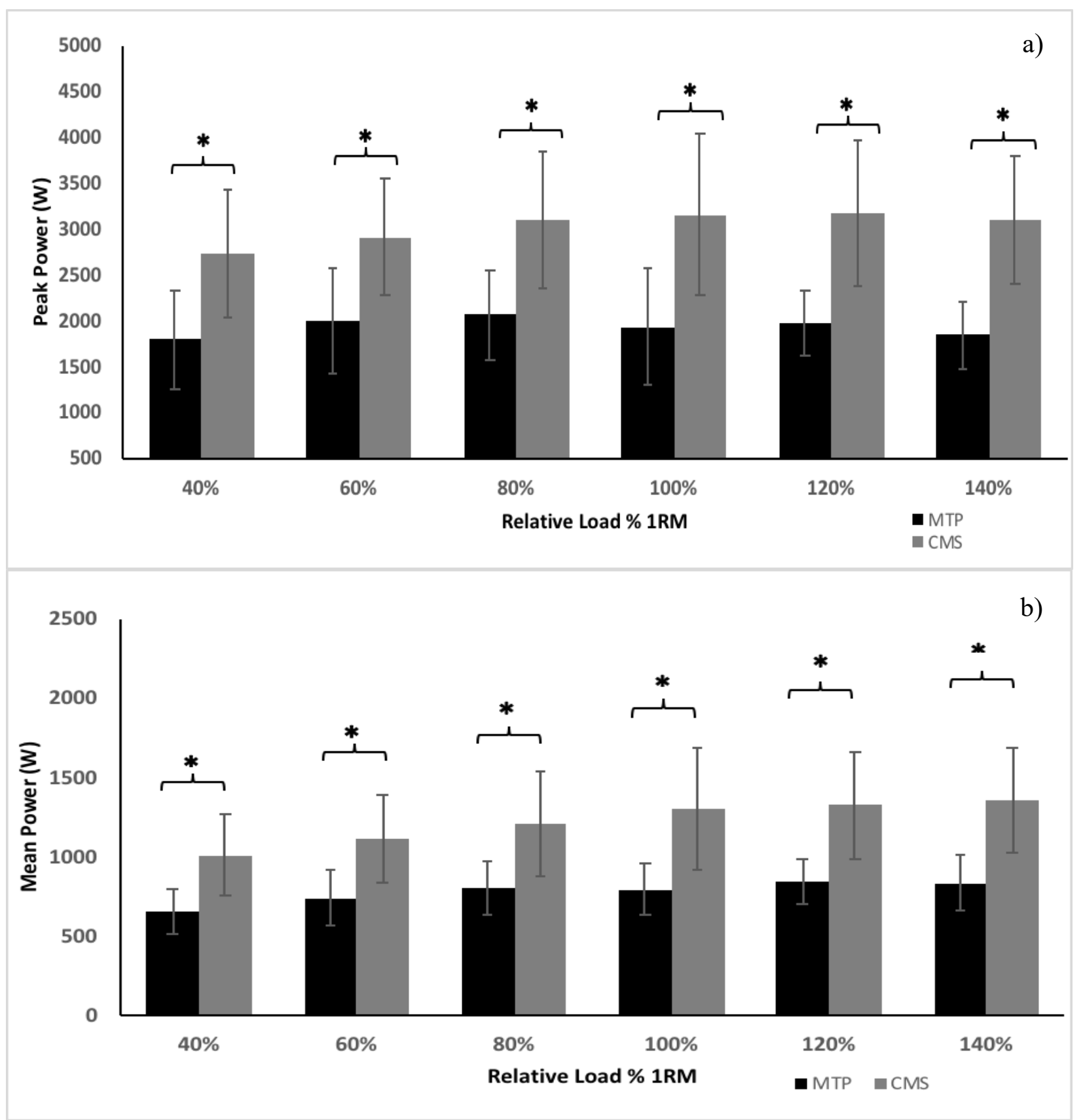

*Significantly greater than MTP $(\mathrm{p}<0.001)$

Figure 4: Comparison of, a) peak power and b) mean power between the countermovement shrug and mid-thigh pull across loads 


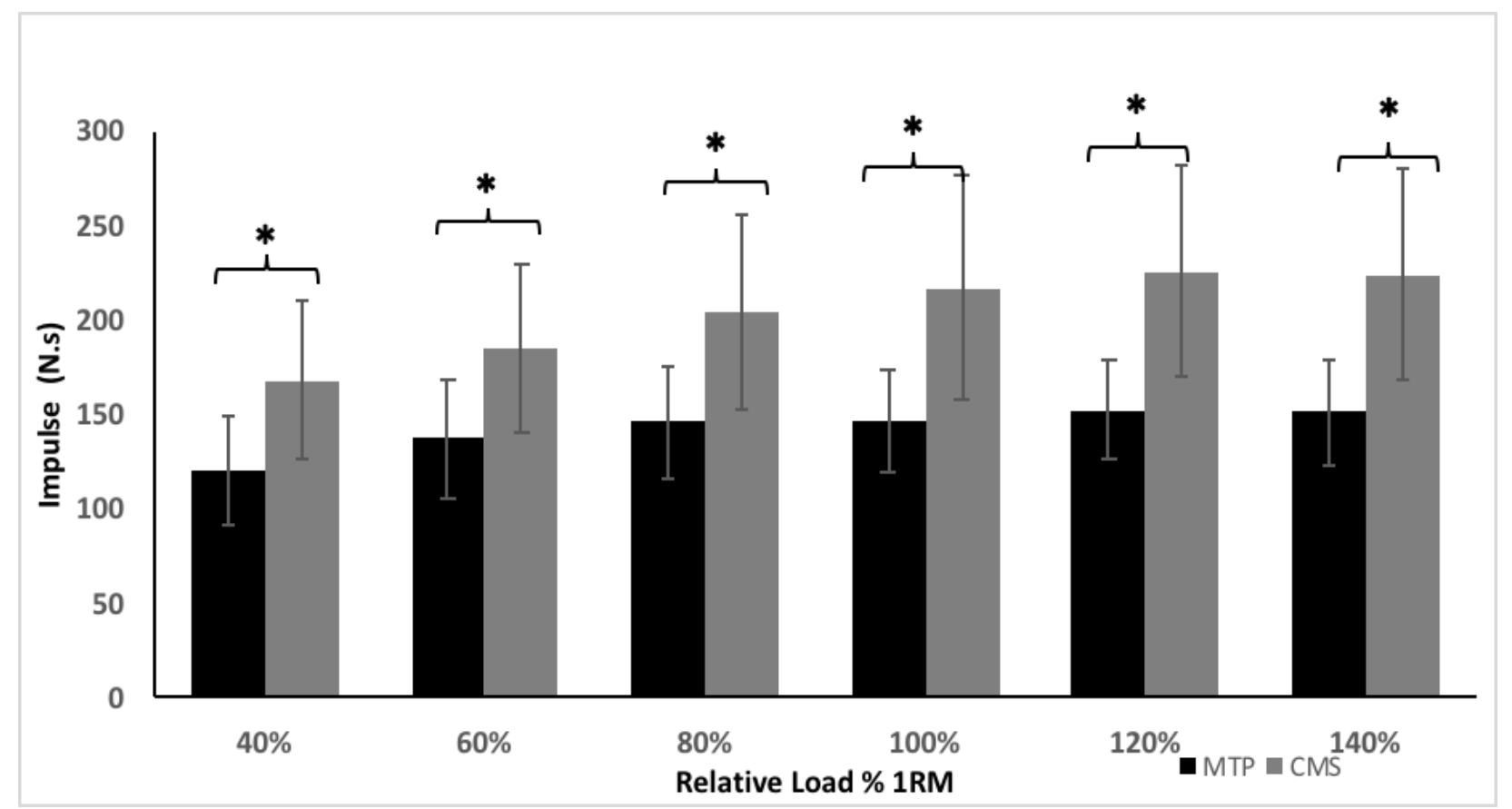

*Significantly greater than MTP $(p<0.001)$

Figure 5: Comparison of impulse between countermovement shrug and mid-thigh pull across loads 


\begin{tabular}{|c|c|c|c|c|c|c|c|c|c|c|c|c|c|}
\hline \multirow[b]{2}{*}{ Variable } & \multirow{2}{*}{$\begin{array}{l}\text { Intensity } \\
\text { Exercise }\end{array}$} & \multicolumn{2}{|c|}{$40 \%$} & \multicolumn{2}{|c|}{$60 \%$} & \multicolumn{2}{|c|}{$80 \%$} & \multicolumn{2}{|c|}{$100 \%$} & \multicolumn{2}{|c|}{$120 \%$} & \multicolumn{2}{|c|}{$140 \%$} \\
\hline & & ICC & $\% \mathrm{CV}$ & ICC & $\% \mathrm{CV}$ & ICC & $\% \mathrm{CV}$ & ICC & $\% \mathrm{CV}$ & ICC & $\% \mathrm{CV}$ & ICC & $\% \mathrm{CV}$ \\
\hline \multirow[t]{2}{*}{$\begin{array}{l}\text { Peak } \\
\text { Force }\end{array}$} & MTP & $\begin{array}{c}0.88 \\
(0.70-0.95)\end{array}$ & $\begin{array}{c}5.5 \% \\
(3.1-8.0)\end{array}$ & $\begin{array}{c}0.84 \\
(0.54-0.94)\end{array}$ & $\begin{array}{c}5.5 \% \\
(3.1-8.0)\end{array}$ & $\begin{array}{c}0.93 \\
(0.83-0.97)\end{array}$ & $\begin{array}{c}3.4 \% \\
(2.2-4.5)\end{array}$ & $\begin{array}{c}0.93 \\
(0.81-0.97)\end{array}$ & $\begin{array}{c}3.8 \% \\
(2.5-5.1)\end{array}$ & $\begin{array}{c}0.89 \\
(0.73-0.96)\end{array}$ & $\begin{array}{c}3.4 \% \\
(1.5-5.3)\end{array}$ & $\begin{array}{c}0.94 \\
(0.85-0.98)\end{array}$ & $\begin{array}{c}4.1 \% \\
(2.7-5.5)\end{array}$ \\
\hline & CMS & $\begin{array}{c}0.95 \\
(0.87-0.98)\end{array}$ & $\begin{array}{c}4.0 \% \\
(2.7-7.0)\end{array}$ & $\begin{array}{c}0.95 \\
(0.87-0.98)\end{array}$ & $\begin{array}{c}4.0 \% \\
(2.5-5.2)\end{array}$ & $\begin{array}{c}0.97 \\
(0.91-0.99)\end{array}$ & $\begin{array}{c}3.0 \% \\
(1.5-3.5)\end{array}$ & $\begin{array}{c}0.99 \\
(0.96-0.99)\end{array}$ & $\begin{array}{c}2.0 \% \\
(1.4-3.3)\end{array}$ & $\begin{array}{c}0.96 \\
(0.91-0.99)\end{array}$ & $\begin{array}{c}3.0 \% \\
(1.5-4.2)\end{array}$ & $\begin{array}{c}0.97 \\
(0.91-0.99)\end{array}$ & $\begin{array}{c}3.0 \% \\
(2.2-4.6)\end{array}$ \\
\hline \multirow[t]{2}{*}{$\begin{array}{l}\text { Mean } \\
\text { Force }\end{array}$} & MTP & $\begin{array}{c}0.88 \\
(0.71-0.95)\end{array}$ & $\begin{array}{c}4.9 \% \\
(2.9-7)\end{array}$ & $\begin{array}{c}0.83 \\
(0.61-0.93)\end{array}$ & $\begin{array}{c}5.9 \% \\
(3.2-8.6)\end{array}$ & $\begin{array}{c}0.93 \\
(0.82-0.97)\end{array}$ & $\begin{array}{c}4.0 \% \\
(2.4-5.6)\end{array}$ & $\begin{array}{c}0.96 \\
(0.90-0.99)\end{array}$ & $\begin{array}{c}3.3 \% \\
(2.4-4.1)\end{array}$ & $\begin{array}{c}0.94 \\
(0.85-0.98)\end{array}$ & $\begin{array}{c}3.6 \% \\
(2.1-5.0)\end{array}$ & $\begin{array}{c}0.98 \\
(0.93-0.99)\end{array}$ & $\begin{array}{c}3.1 \% \\
(2.3-3.9)\end{array}$ \\
\hline & CMS & $\begin{array}{c}0.98 \\
(0.94-0.99)\end{array}$ & $\begin{array}{c}3.0 \% \\
(1.7-3.4)\end{array}$ & $\begin{array}{c}0.96 \\
(0.89-0.98)\end{array}$ & $\begin{array}{c}3.0 \% \\
(1.0-4.0)\end{array}$ & $\begin{array}{c}0.98 \\
(0.93-0.99)\end{array}$ & $\begin{array}{c}2.0 \% \\
(1.3-2.9)\end{array}$ & $\begin{array}{c}0.99 \\
(0.97-0.99)\end{array}$ & $\begin{array}{c}2.0 \% \\
(1.5-2.3)\end{array}$ & $\begin{array}{c}0.99 \\
(0.97-0.99)\end{array}$ & $\begin{array}{c}1.0 \% \\
(0.7-2.7)\end{array}$ & $\begin{array}{c}0.98 \\
(0.95-0.99)\end{array}$ & $\begin{array}{c}2.0 \% \\
(1.3-3.0)\end{array}$ \\
\hline \multirow[t]{2}{*}{$\begin{array}{l}\text { Peak } \\
\text { Velocity }\end{array}$} & MTP & $\begin{array}{c}0.72 \\
(0.38-0.89)\end{array}$ & $\begin{array}{c}9.0 \% \\
(4.2-13.9)\end{array}$ & $\begin{array}{c}0.74 \\
(0.44-0.89)\end{array}$ & $\begin{array}{c}7.7 \% \\
(3.8-11.7)\end{array}$ & $\begin{array}{c}0.90 \\
(0.75-0.96)\end{array}$ & $\begin{array}{c}4.4 \% \\
(2.5-6.3)\end{array}$ & $\begin{array}{c}0.79 \\
(0.44-0.92)\end{array}$ & $\begin{array}{c}6.1 \% \\
(3.8-8.4)\end{array}$ & $\begin{array}{c}0.92 \\
(0.81-0.97)\end{array}$ & $\begin{array}{c}3.3 \% \\
(2.0-4.6)\end{array}$ & $\begin{array}{c}0.87 \\
(0.69-0.95)\end{array}$ & $\begin{array}{c}4.9 \% \\
(3.5-6.3)\end{array}$ \\
\hline & CMS & $\begin{array}{c}0.70 \\
(0.34-0.86)\end{array}$ & $\begin{array}{c}4.0 \% \\
(2.9-5.4)\end{array}$ & $\begin{array}{c}0.71 \\
(0.38-0.88)\end{array}$ & $\begin{array}{c}4.0 \% \\
(2.5-5.7)\end{array}$ & $\begin{array}{c}0.76 \\
(0.45-0.90)\end{array}$ & $\begin{array}{c}3.0 \% \\
(1.8-5.1)\end{array}$ & $\begin{array}{c}0.94 \\
(0.85-0.98)\end{array}$ & $\begin{array}{c}3.0 \% \\
(1.7-3.5)\end{array}$ & $\begin{array}{c}0.89 \\
(0.72-0.96)\end{array}$ & $\begin{array}{c}3.0 \% \\
(2.1-4.1)\end{array}$ & $\begin{array}{c}0.87 \\
(0.69-0.95)\end{array}$ & $\begin{array}{c}3.0 \% \\
(1.7-4.8)\end{array}$ \\
\hline \multirow[t]{2}{*}{$\begin{array}{l}\text { Mean } \\
\text { Velocity }\end{array}$} & MTP & $\begin{array}{c}0.71 \\
(0.39-0.88)\end{array}$ & $\begin{array}{c}9.7 \% \\
(4.9-14.5)\end{array}$ & $\begin{array}{c}0.67 \\
(0.33-0.86)\end{array}$ & $\begin{array}{c}10 \% \\
(4.5-15.6)\end{array}$ & $\begin{array}{c}0.76 \\
(0.47-0.90)\end{array}$ & $\begin{array}{c}7.7 \% \\
(4.6-10.8)\end{array}$ & $\begin{array}{c}0.65 \\
(0.17-0.87)\end{array}$ & $\begin{array}{c}8.9 \% \\
(6.2-11.6)\end{array}$ & $\begin{array}{c}0.64 \\
(0.25-0.85)\end{array}$ & $\begin{array}{c}7.7 \% \\
(5.3-10.2)\end{array}$ & $\begin{array}{c}0.68 \\
(0.32-0.87)\end{array}$ & $\begin{array}{c}7.0 \% \\
(4.1-10)\end{array}$ \\
\hline & CMS & $\begin{array}{c}0.65 \\
(0.27-0.85)\end{array}$ & $\begin{array}{c}5.0 \% \\
(3.5-6.1)\end{array}$ & $\begin{array}{c}0.54 \\
(0.13-0.79)\end{array}$ & $\begin{array}{c}4.0 \% \\
(1.7-6.4)\end{array}$ & $\begin{array}{c}0.69 \\
(0.35-0.87)\end{array}$ & $\begin{array}{c}4.0 \% \\
(1.0-6.4)\end{array}$ & $\begin{array}{c}0.90 \\
(0.74-0.96)\end{array}$ & $\begin{array}{c}3.0 \% \\
(2.0-4.7)\end{array}$ & $\begin{array}{c}0.87 \\
(0.69-0.95)\end{array}$ & $\begin{array}{c}3.0 \% \\
(1.5-4.7)\end{array}$ & $\begin{array}{c}0.93 \\
(0.83-0.97)\end{array}$ & $\begin{array}{c}3.0 \% \\
(1.9-5.0)\end{array}$ \\
\hline \multirow[t]{2}{*}{$\begin{array}{l}\text { Peak } \\
\text { Power }\end{array}$} & MTP & $\begin{array}{c}0.76 \\
(0.47-0.91)\end{array}$ & $\begin{array}{c}13.0 \% \\
(7.1-18.8)\end{array}$ & $\begin{array}{c}0.77 \\
(0.50-0.91)\end{array}$ & $\begin{array}{c}10.7 \% \\
(5.8-15.6)\end{array}$ & $\begin{array}{c}0.91 \\
(0.78-0.97)\end{array}$ & $\begin{array}{c}5.9 \% \\
(3.9-7.9)\end{array}$ & $\begin{array}{c}0.75 \\
(0.39-0.94)\end{array}$ & $\begin{array}{c}7.8 \% \\
(4.5-11.0)\end{array}$ & $\begin{array}{c}0.86 \\
(0.67-0.94)\end{array}$ & $\begin{array}{c}4.2 \% \\
(2.0-6.5)\end{array}$ & $\begin{array}{c}0.85 \\
(0.64-0.94)\end{array}$ & $\begin{array}{c}6.4 \% \\
(4.6-8.3)\end{array}$ \\
\hline & CMS & $\begin{array}{c}0.94 \\
(0.84-0.98)\end{array}$ & $\begin{array}{c}5.0 \% \\
(4.1-6.8)\end{array}$ & $\begin{array}{c}0.89 \\
(0.73-0.96)\end{array}$ & $\begin{array}{c}6.0 \% \\
(3.6-8.0)\end{array}$ & $\begin{array}{c}0.93 \\
(0.84-0.98)\end{array}$ & $\begin{array}{c}4.0 \% \\
(2.7-5.8)\end{array}$ & $\begin{array}{c}0.98 \\
(0.92-0.99)\end{array}$ & $\begin{array}{c}4.0 \% \\
2.4-5.1)\end{array}$ & $\begin{array}{c}0.95 \\
(0.87-0.98)\end{array}$ & $\begin{array}{c}4.0 \% \\
(2.6-5.1)\end{array}$ & $\begin{array}{c}0.95 \\
(0.86-0.98)\end{array}$ & $\begin{array}{c}4.0 \% \\
(2.4-6.2)\end{array}$ \\
\hline \multirow[t]{2}{*}{$\begin{array}{l}\text { Mean } \\
\text { Power }\end{array}$} & MTP & $\begin{array}{c}0.76 \\
(0.46-0.94)\end{array}$ & $\begin{array}{c}9.9 \% \\
(5.9-13.9)\end{array}$ & $\begin{array}{c}0.80 \\
(0.60-0.92)\end{array}$ & $\begin{array}{c}8.4 \% \\
(4.2-12.6)\end{array}$ & $\begin{array}{c}0.90 \\
(0.75-0.96)\end{array}$ & $\begin{array}{c}5.9 \% \\
(3.6-8.1)\end{array}$ & $\begin{array}{c}0.84 \\
(0.33-0.95)\end{array}$ & $\begin{array}{c}7.1 \% \\
(5.1-9.1)\end{array}$ & $\begin{array}{c}0.81 \\
(0.50-0.93)\end{array}$ & $\begin{array}{c}5.8 \% \\
(3.5-8.1)\end{array}$ & $\begin{array}{c}0.89 \\
(0.74-0.96)\end{array}$ & $\begin{array}{c}5.8 \% \\
(3.6-8.1)\end{array}$ \\
\hline & CMS & $\begin{array}{c}0.96 \\
(0.90-0.99)\end{array}$ & $\begin{array}{c}4.0 \% \\
(2.9-5.4)\end{array}$ & $\begin{array}{c}0.93 \\
(0.82-0.97)\end{array}$ & $\begin{array}{c}5.0 \% \\
(2.2-6.9)\end{array}$ & $\begin{array}{c}0.90 \\
(0.75-0.96)\end{array}$ & $\begin{array}{c}3.0 \% \\
(0.9-5.8)\end{array}$ & $\begin{array}{c}0.97 \\
(0.89-0.99)\end{array}$ & $\begin{array}{c}3.0 \% \\
(1.5-4.3)\end{array}$ & $\begin{array}{c}0.95 \\
(0.87-0.98)\end{array}$ & $\begin{array}{c}3.0 \% \\
(1.4-4.8)\end{array}$ & $\begin{array}{c}0.96 \\
(0.88-0.98)\end{array}$ & $\begin{array}{c}3.0 \% \\
(1.7-5.0)\end{array}$ \\
\hline \multirow[t]{2}{*}{ Impulse } & MTP & $\begin{array}{c}0.81 \\
(0.56-0.93)\end{array}$ & $\begin{array}{c}8.9 \% \\
(4.5-13.5)\end{array}$ & $\begin{array}{c}0.80 \\
(0.55-0.92)\end{array}$ & $\begin{array}{c}7.9 \% \\
(4.0-11.8)\end{array}$ & $\begin{array}{c}0.92 \\
(0.80-0.97)\end{array}$ & $\begin{array}{c}4.5 \% \\
(2.6-6.5)\end{array}$ & $\begin{array}{c}0.84 \\
(0.60-0.94)\end{array}$ & $\begin{array}{c}6.2 \% \\
(3.8-8.5)\end{array}$ & $\begin{array}{c}0.86 \\
(0.67-0.95)\end{array}$ & $\begin{array}{c}4.0 \% \\
(1.1-6.9)\end{array}$ & $\begin{array}{c}0.90 \\
(0.76-0.96)\end{array}$ & $\begin{array}{c}5.1 \% \\
(3.7-6.5)\end{array}$ \\
\hline & CMS & $\begin{array}{c}0.96 \\
(0.89-0.98)\end{array}$ & $\begin{array}{c}4.0 \% \\
(2.8-5.4)\end{array}$ & $\begin{array}{c}0.96 \\
(0.89-0.98)\end{array}$ & $\begin{array}{c}4.0 \% \\
(2.7-5.7)\end{array}$ & $\begin{array}{c}0.95 \\
(0.86-0.98)\end{array}$ & $\begin{array}{c}3.0 \% \\
(1.6-4.8)\end{array}$ & $\begin{array}{c}0.99 \\
(0.95-0.99)\end{array}$ & $\begin{array}{c}3.0 \% \\
(1.7-3.4)\end{array}$ & $\begin{array}{c}0.96 \\
(0.91-0.97)\end{array}$ & $\begin{array}{c}3.0 \% \\
(2.2-4.3)\end{array}$ & $\begin{array}{c}0.96 \\
(0.90-0.99)\end{array}$ & $\begin{array}{c}4.0 \% \\
(2.2-6.0)\end{array}$ \\
\hline
\end{tabular}




\begin{tabular}{|c|c|c|c|c|c|c|c|c|c|c|c|c|c|}
\hline \multirow[t]{2}{*}{$\begin{array}{l}\text { Barbell } \\
\text { Velocity }\end{array}$} & MTP & $\begin{array}{c}0.94 \\
(0.84-0.98)\end{array}$ & $\begin{array}{c}3.6 \% \\
(2.2-4.9)\end{array}$ & $\begin{array}{c}0.89 \\
(0.73-0.96)\end{array}$ & $\begin{array}{c}3.5 \% \\
(1.9-5.0)\end{array}$ & $\begin{array}{c}0.96 \\
(0.89-0.98)\end{array}$ & $\begin{array}{c}2.6 \% \\
(1.7-3.6)\end{array}$ & $\begin{array}{c}0.96 \\
(0.89-0.98)\end{array}$ & $\begin{array}{c}2.5 \% \\
(1.3-3.6)\end{array}$ & $\begin{array}{c}0.90 \\
(0.75-0.96)\end{array}$ & $\begin{array}{c}3.0 \% \\
(1.0-5.0)\end{array}$ & $\begin{array}{c}0.93 \\
(0.81-0.97)\end{array}$ & $\begin{array}{c}2.6 \% \\
(1.3-4.0)\end{array}$ \\
\hline & CMS & $\begin{array}{c}0.95 \\
(0.88-0.98)\end{array}$ & $\begin{array}{c}2.0 \% \\
(0.9-2.2)\end{array}$ & $\begin{array}{c}0.91 \\
(0.78-0.97)\end{array}$ & $\begin{array}{c}2.0 \% \\
(1.3-2.9)\end{array}$ & $\begin{array}{c}0.79 \\
(0.52-0.92)\end{array}$ & $\begin{array}{c}2.0 \% \\
(1.0-3.6)\end{array}$ & $\begin{array}{c}0.94 \\
(0.86-0.98)\end{array}$ & $\begin{array}{c}2.0 \% \\
(1.2-2.8)\end{array}$ & $\begin{array}{c}0.81 \\
(0.55-0.92)\end{array}$ & $\begin{array}{c}3.0 \% \\
(1.6-4.0)\end{array}$ & $\begin{array}{c}0.91 \\
(0.79-0.97\end{array}$ & $\begin{array}{c}3.0 \% \\
(1.7-3.5)\end{array}$ \\
\hline
\end{tabular}

Table 1- Reliability (ICC [95\% confidence intervals) and variability $(\% \mathrm{CV})[95 \%$ confidence intervals) of kinetic and kinematic variables during the countermovement shrug and mid-thigh pull 
Table 2a: Descriptive statistics (mean, standard deviation and $95 \%$ confidence intervals) for the mid-thigh pull

\begin{tabular}{|c|c|c|c|c|c|c|c|}
\hline Intensity & $\begin{array}{c}\text { Peak Force } \\
(\mathrm{N})\end{array}$ & $\begin{array}{c}\text { Mean Force } \\
(\mathbf{N})\end{array}$ & $\begin{array}{c}\text { Peak Velocity } \\
\left(\mathrm{m} . \mathrm{s}^{-1}\right)\end{array}$ & $\begin{array}{l}\text { Peak Power } \\
\text { (W) }\end{array}$ & $\begin{array}{l}\text { Mean Power } \\
\text { (W) }\end{array}$ & $\begin{array}{c}\text { Impulse } \\
\left(\mathrm{N} . \mathrm{s}^{-1}\right)\end{array}$ & $\begin{array}{c}\text { Barbell } \\
\text { Velocity }\left(\mathrm{m} . \mathrm{s}^{-1}\right) \\
\end{array}$ \\
\hline $40 \%$ & $\begin{array}{c}2411 \pm 424 \\
(2200-2622)\end{array}$ & $\begin{array}{c}1851 \pm 311 \\
(1696-2006)\end{array}$ & $\begin{array}{l}1.03 \pm 0.22 \\
(0.93-0.14)\end{array}$ & $\begin{array}{c}1789 \pm 537 \\
(1522-2056)\end{array}$ & $\begin{array}{l}651 \pm 144 \\
(581-725)\end{array}$ & $\begin{array}{c}120 \pm 29 \\
(106-134)\end{array}$ & $\begin{array}{c}\mathbf{1 . 5 3}^{\mathbf{5}} \mathbf{\text { 0.25*}} \\
(1.40-1.65)\end{array}$ \\
\hline $60 \%$ & $\begin{array}{c}2630 \pm 434 \\
(2414-2846)\end{array}$ & $\begin{array}{c}2064 \pm 368 \\
(1881-2247)\end{array}$ & $\begin{array}{c}\mathbf{1 . 0 5} \pm \mathbf{0 . 2 1} * \\
(0.94-1.15)\end{array}$ & $\begin{array}{c}2005 \pm 574 \\
(1719-2290)\end{array}$ & $\begin{array}{l}740 \pm 180 \\
(652-828)\end{array}$ & $\begin{array}{c}137 \pm 32 \\
(121-153)\end{array}$ & $\begin{array}{l}1.47 \pm 0.20 \\
(1.37-1.57)\end{array}$ \\
\hline $80 \%$ & $\begin{array}{c}2835 \pm 451 \\
(2611-3060)\end{array}$ & $\begin{array}{c}2255 \pm 387 \\
(2702-3208)\end{array}$ & $\begin{array}{l}1.00 \pm 0.12 \\
(0.91-1.08)\end{array}$ & $\begin{array}{l}2063 \pm 491 * \\
(1819-2308)\end{array}$ & $\begin{array}{l}799 \pm 167 \\
(715-882)\end{array}$ & $\begin{array}{c}147 \pm 30 \\
(132-162)\end{array}$ & $\begin{array}{l}1.34 \pm 0.19 \\
(1.24-1.43)\end{array}$ \\
\hline $100 \%$ & $\begin{array}{c}2955 \pm 509 \\
(2702-3208)\end{array}$ & $\begin{array}{c}2354 \pm 446 \\
(2132-2576)\end{array}$ & $\begin{array}{l}0.89 \pm 0.14 \\
(0.82-0.96)\end{array}$ & $\begin{array}{c}1929 \pm 365 \\
(1748-2110)\end{array}$ & $\begin{array}{l}797 \pm 158 \\
(717-874)\end{array}$ & $\begin{array}{c}147 \pm 28 \\
(133-161)\end{array}$ & $\begin{array}{l}1.15 \pm 0.17 \\
(1.07-1.23)\end{array}$ \\
\hline $120 \%$ & $\begin{array}{c}3065 \pm 514 \\
(2809-3320)\end{array}$ & $\begin{array}{c}2512 \pm 465 \\
(2280-2743)\end{array}$ & $\begin{array}{l}0.86 \pm 0.13 \\
(0.80-0.93)\end{array}$ & $\begin{array}{c}1973 \pm 347 \\
(1800-2146)\end{array}$ & $\begin{array}{c}\mathbf{8 4 9} \pm \mathbf{1 4 4} * \\
(777-919)\end{array}$ & $\begin{array}{l}\text { 152 } \pm \text { 26** } \\
(139-166)\end{array}$ & $\begin{array}{l}1.07 \pm 0.15 \\
(0.99-1.14)\end{array}$ \\
\hline $140 \%$ & $\begin{array}{l}\text { 3135 } \pm \text { 622* } \\
(2826-3445)\end{array}$ & $\begin{array}{l}\mathbf{2 6 4 6}^{\mathbf{5} 5 \mathbf{5 4 3} *} \\
(2376-2916)\end{array}$ & $\begin{array}{l}0.77 \pm 0.12 \\
(0.71-0.82)\end{array}$ & $\begin{array}{c}1839 \pm 375 \\
(1669-2009)\end{array}$ & $\begin{array}{l}835 \pm 174 \\
(749-921)\end{array}$ & $\begin{array}{c}151 \pm 28 \\
(137-165)\end{array}$ & $\begin{array}{l}0.97 \pm 0.14 \\
(0.89-1.03)\end{array}$ \\
\hline
\end{tabular}


Table 2b: Comparisons of kinetic and kinematic variables between loads during the mid-thigh pull using Hedges' g effect size

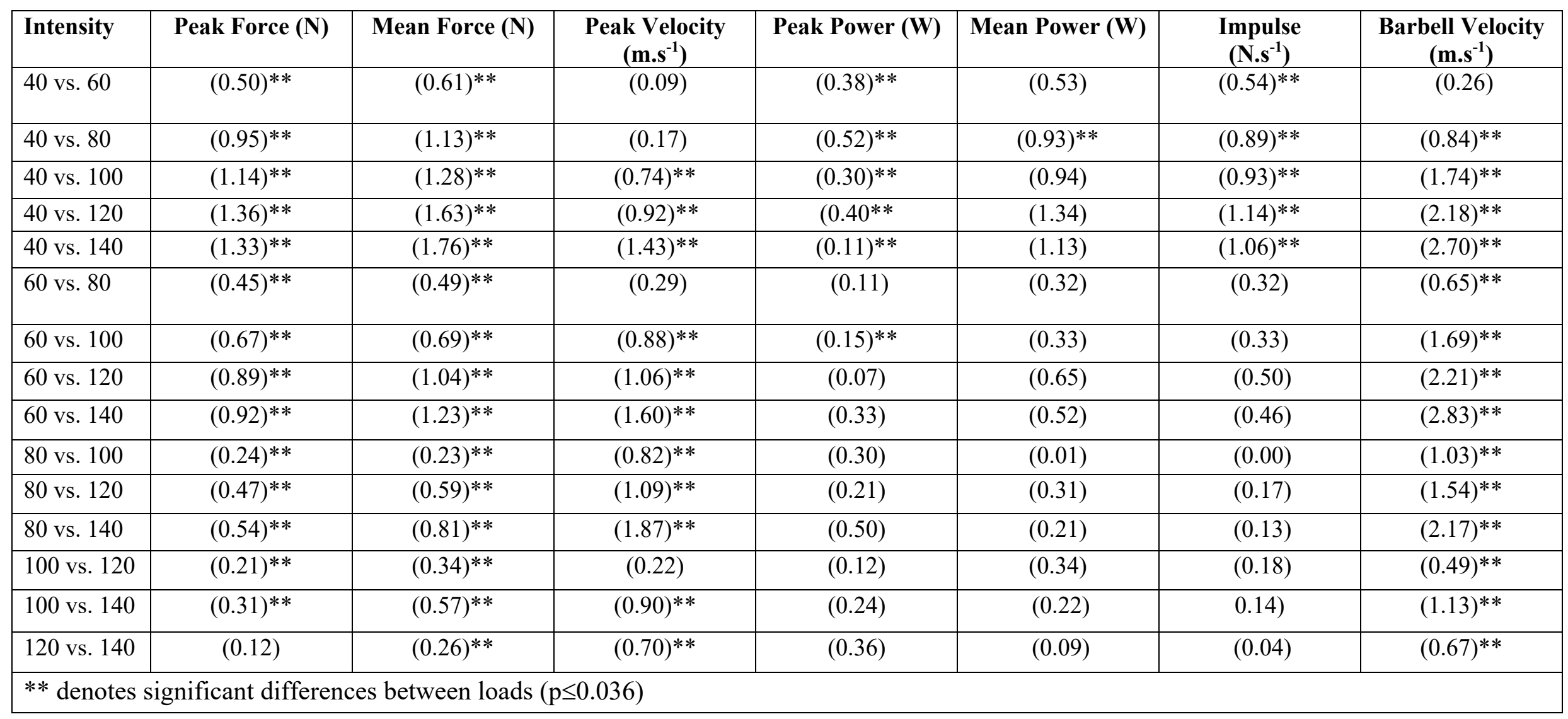


Table 3a: Descriptive statistics (mean, standard deviation and $95 \%$ confidence intervals) for the countermovement shrug

\begin{tabular}{|c|c|c|c|c|c|c|c|}
\hline Intensity & $\begin{array}{l}\text { Peak Force } \\
(\mathbf{N})\end{array}$ & $\begin{array}{l}\text { Mean Force } \\
\text { (N) }\end{array}$ & $\begin{array}{c}\text { Peak Velocity } \\
\left(\mathrm{m} . \mathrm{s}^{-1}\right)\end{array}$ & $\begin{array}{c}\text { Peak Power } \\
\text { (W) }\end{array}$ & $\begin{array}{c}\text { Mean Power } \\
\text { (W) }\end{array}$ & $\begin{array}{c}\text { Impulse } \\
\left(\mathrm{N} . \mathrm{s}^{-1}\right)\end{array}$ & $\begin{array}{c}\text { Barbell } \\
\text { Velocity }\left(\mathrm{m} . \mathrm{s}^{-1}\right)\end{array}$ \\
\hline $40 \%$ & $\begin{array}{c}2891 \pm 603 \\
(2591-3191)\end{array}$ & $\begin{array}{c}2334 \pm 853 \\
(2109-2559)\end{array}$ & $\begin{array}{c}* \mathbf{1 . 3 9} \pm \mathbf{0 . 1 2} \\
(1.33-1.45)\end{array}$ & $\begin{array}{c}2738 \pm 697 \\
(2391-3085)\end{array}$ & $\begin{array}{l}1010 \pm 260 \\
(881-1139)\end{array}$ & $\begin{array}{c}168 \pm 43 \\
(146-189)\end{array}$ & $\begin{array}{l}\mathbf{1 . 9 6} \pm \mathbf{0 . 1 8 *} \\
(1.87-2.05)\end{array}$ \\
\hline $60 \%$ & $\begin{array}{c}3048 \pm 648 \\
(2726-3370)\end{array}$ & $\begin{array}{c}2512 \pm 510 \\
(2259-2766)\end{array}$ & $\begin{array}{l}1.37 \pm 0.12 \\
(1.31-1.43)\end{array}$ & $\begin{array}{c}2910 \pm 643 \\
(2590-3230)\end{array}$ & $\begin{array}{l}1113 \pm 276 \\
(946-1250)\end{array}$ & $\begin{array}{c}185 \pm 45 \\
(163-208)\end{array}$ & $\begin{array}{l}1.79 \pm 0.16 \\
(1.72-1.81)\end{array}$ \\
\hline $80 \%$ & $\begin{array}{c}3236 \pm 704 \\
(2886-3586)\end{array}$ & $\begin{array}{c}2706 \pm 553 \\
(2431-2981)\end{array}$ & $\begin{array}{l}1.34 \pm 0.12 \\
(1.28-1.40)\end{array}$ & $\begin{array}{c}3093 \pm 736 \\
(2727-3460)\end{array}$ & $\begin{array}{c}1208 \pm 332 \\
(1043-1374)\end{array}$ & $\begin{array}{c}204 \pm 52 \\
(178-230)\end{array}$ & $\begin{array}{l}1.64 \pm 0.12 \\
(1.58-1.70)\end{array}$ \\
\hline $100 \%$ & $\begin{array}{l}3413 \pm 821 \\
3004-3821)\end{array}$ & $\begin{array}{c}2783 \pm 641 \\
(2554-3192)\end{array}$ & $\begin{array}{l}1.29 \pm 0.17 \\
(1.21-1.38)\end{array}$ & $\begin{array}{l}3151 \pm 877 \\
(2715-3587\end{array}$ & $\begin{array}{c}1297 \pm 384 \\
(1106-1488)\end{array}$ & $\begin{array}{c}217 \pm 59 \\
(188-247)\end{array}$ & $\begin{array}{l}1.50 \pm 0.16 \\
(1.42-1.58)\end{array}$ \\
\hline $120 \%$ & $\begin{array}{c}3550 \pm 845 \\
(3130-3971)\end{array}$ & $\begin{array}{c}3022 \pm 665 \\
(2691-2988)\end{array}$ & $\begin{array}{l}1.22 \pm 0.13 \\
(1.16-1.29)\end{array}$ & $\begin{array}{l}3160 \pm 796 * \\
(2764-3556)\end{array}$ & $\begin{array}{c}1322 \pm 344 \\
(1151-1493)\end{array}$ & $\begin{array}{l}\mathbf{2 2 6} \pm \mathbf{5 6} * \\
(198-254)\end{array}$ & $\begin{array}{l}1.38 \pm 0.11 \\
(1.33-1.44)\end{array}$ \\
\hline $140 \%$ & $\begin{array}{l}3640 \pm 814 * \\
(3235-4045)\end{array}$ & $\begin{array}{l}\text { 3143 } \pm \text { 632* } \\
(2829-3457)\end{array}$ & $\begin{array}{l}1.15 \pm 0.14 \\
(1.07-1.22)\end{array}$ & $\begin{array}{c}3100 \pm 692 \\
(2756-3444)\end{array}$ & $\begin{array}{l}1353 \pm 331 * \\
(1188-1517)\end{array}$ & $\begin{array}{c}225 \pm 56 \\
(197-253)\end{array}$ & $\begin{array}{l}1.27 \pm 0.14 \\
(1.20-1.34)\end{array}$ \\
\hline
\end{tabular}


3b: Comparison of kinetic and kinematic variables between loads during the Countermovement Shrug using Hedges' g effect sizes

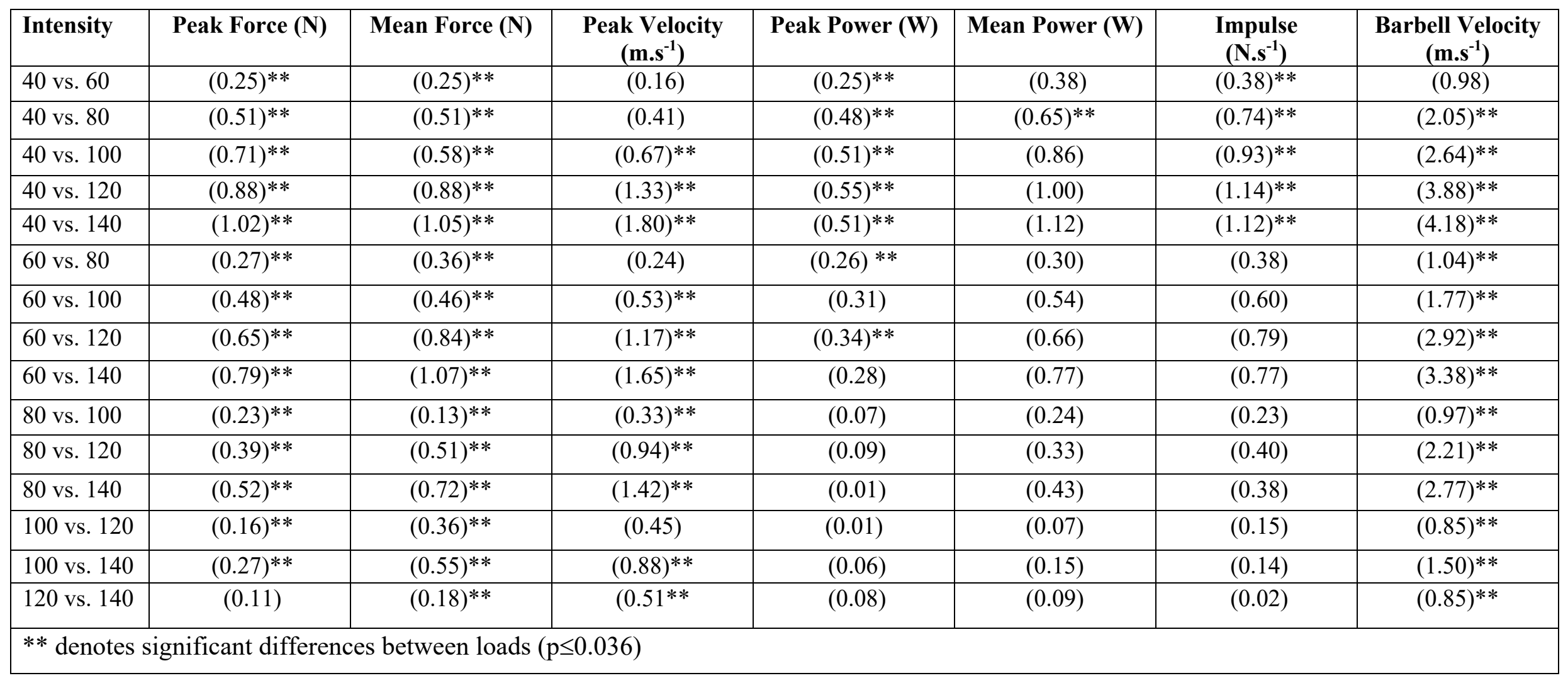


